\title{
Angioplasty at an invasive treatment centre reduced mortality compared with first contact thrombolysis
}

Andersen HR, Nielsen TT, Rasmussen K, et al. A comparison of coronary angioplasty with fibrinolytic therapy in acute myocardial infarction. N Engl J Med 2003;349:733-42.

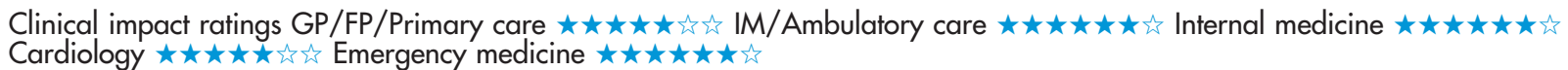

Is the transfer of patients with ST-segment elevation myocardial infarction (STEMI) to an invasive treatment centre (ITC) for primary angioplasty (percutaneous coronary intervention [PCI]) more effective than onsite fibrinolysis for reducing all cause mortality, reinfarction, or stroke?

METHODS

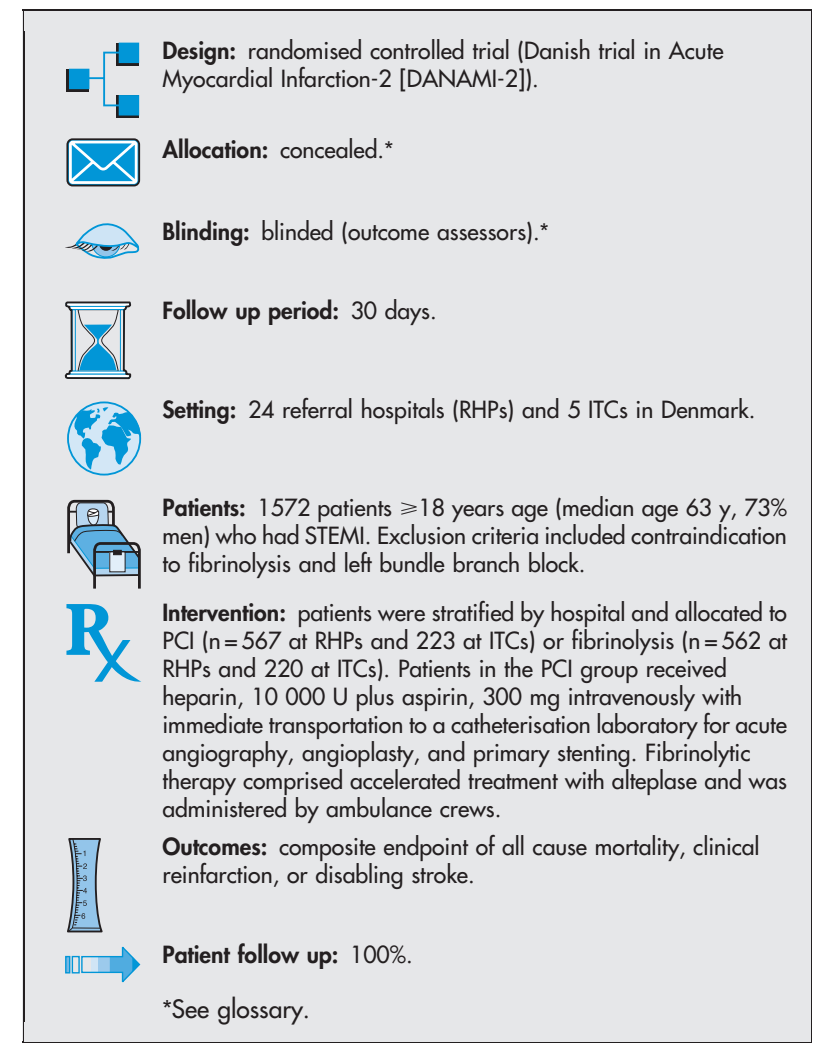

\section{MAIN RESULTS}

Analysis was by intention to treat. $96 \%$ of patients allocated to PCI at RHPs were transferred to an ITC $\leqslant 2$ hours after admission. Among all patients combined and among patients randomised at RHPs or ITCs separately, the rate of the composite endpoint was lower in the PCI group than in the fibrinolysis group (table).

For correspondence: Dr H R Andersen, Aarhus University Hospital, Aarhus, Denmark. henning.rud.andersen@iekf.au.dk

Sources of funding: Danish Heart Foundation; Danish Medical Research Council; AstraZeneca; Bristol-Myers Squibb; Cordis; Pfizer; PharmaciaUpjohn; Boehringer Ingelheim; Guerbet.

\section{CONCLUSION}

The transfer of patients who have had myocardial infarction with STsegment elevation to an invasive treatment centre for primary percutaneous coronary intervention was more effective than onsite fibrinolysis for reducing all cause mortality, reinfarction, or stroke.

Abstract and commentary also appear in ACP Journal Club.

\section{Commentary}

Diming rima imary $\mathrm{PCl}$ offers advantages over fibrinolytic therapy when done promptly in excellent $\mathrm{PCl}$ centres. ${ }^{1}$ However, the conclusion from DANAMI-2 that hospitals without PCI capability must withhold fibrinolytic therapy and transfer patients for primary $\mathrm{PCl}$ because of the reduction in the composite endpoint of death, reinfarction, or disabling stroke compared with onsite fibrinolytic therapy deserves further scrutiny because of study design.

The composite endpoint was driven by the reduction in reinfarction rates with primary $\mathrm{PCl}$. Trends for mortality and disabling stroke reduction with $\mathrm{PCl}$ were statistically insignificant. It is important to note that in the fibrinolysis group, rescue $\mathrm{PCl}$ was only used in $2 \%$ of patients and reinfarction was treated with repeated fibrinolysis instead of angioplasty. With a 30 day mortality rate of $24 \%$ after reinfarction, approximately 7 excess deaths occurred in the fibrinolysis group because of this complication. The use of low molecular weight heparin instead of unfractionated heparin and a more liberal policy of permitting angioplasty to treat recurrent ischaemia in the fibrinolysis group probably would have decreased reinfarction rates and equalized mortality rates. Additionally, the stroke rate in the fibrinolysis group was higher than noted in previous fibrinolysis megatrials: Whether the higher than currently recommended unfractionated heparin dosing used in this study or the repeated fibrinolysis infusion in 26 patients contributed to this excess was not discussed. In transfer patients, time to $\mathrm{PCl}$ was only 90 minutes because of a superbly organised national MI triage system, compared with 185 minutes in the US in $2002{ }^{2}$

Unless local emergency transport programmes can deliver patients to $\mathrm{PCl}$ centres within the times observed in this study, fibrinolytic therapy should be the preferred treatment strategy for patients who present to hospitals without $\mathrm{PCl}$ capability. In such settings, emergency transfer to $\mathrm{PCl}$ centres should be reserved for moderate and high risk patients in whom reperfusion fails or for those who develop recurrent ischaemia.

Eric R Bates, MD University of Michigan Ann Arbor, Michigan, USA

1 Keeley EC, Boura JA, Grines CL. Primary angioplasty verses intravenous thrombolytic therapy for acute myocardial infarction: a quantitative review of 23 randomised trials. Lancet 2003;361:13-20.

2 The National Registry of Myocardial Infarction-4 Quarterly Report. South San Francisco, CA: Genentech, March 2003.

Percutaneous coronary intervention (PCI) $v$ onsite fibrinolysis for myocardial infarction at 30 days*

\begin{tabular}{llllll}
\hline Outcome & Site of randomisation & PCI & Fibrinolysis & RRR (95\% CI) & NNT (CI) \\
\hline Composite endpoint & All patients & $8.0 \%$ & $13.7 \%$ & $42 \%$ (22 to 57$)$ & 18 (12 to 38$)$ \\
& RHs & $8.5 \%$ & $14.2 \%$ & $41 \%$ (17 to 58) & 18 (11 to 48$)$ \\
& ITCs & $6.7 \%$ & $12.3 \%$ & $45 \%$ (0.9 to 70) & 19 (9 to 1153) \\
\hline
\end{tabular}

${ }^{*}$ Composite endpoint = all cause mortality, clinical reinfarction, or disabling stroke; $\mathrm{RH} s=$ referral hospitals; ITCs = invasive treatment centres. Other abbreviations defined in glossary; RRR, NNT, and $\mathrm{Cl}$ calculated from data in article. 